Article

\title{
A Robust Liquid Chromatographic Method for Confirmation of Drug Stability of Azithromycin in Bulk Samples, Tablets and Suspensions
}

\author{
Alex O. Okaru ${ }^{1, *}$, Kennedy O. Abuga ${ }^{1}$, Franco N. Kamau ${ }^{1}$, Stanley N. Ndwigah ${ }^{1}$ and \\ Dirk W. Lachenmeier ${ }^{2}$ \\ 1 Department of Pharmaceutical Chemistry, University of Nairobi, Off Ngong Road, Nairobi, \\ P.O. Box 19676-00202 Nairobi, Kenya; koabuga@uonbi.ac.ke (K.O.A.); \\ franco.kamau@uonbi.ac.ke (F.N.K.); snndwigah@uonbi.ac.ke (S.N.N.) \\ 2 Chemisches und Veterinäruntersuchungsamt (CVUA) Karlsruhe, Weissenburger Straße 3, 76187 Karlsruhe, \\ Germany; lachenmeier@web.de \\ * Correspondence: alex.okaru@gmail.com; Tel.: +254-726-53-9193
}

Academic Editor: Beverley D. Glass

Received: 4 January 2017; Accepted: 15 February 2017; Published: 24 February 2017

\begin{abstract}
A simple, isocratic and robust RP-HPLC method for the analysis of azithromycin was developed, validated and applied for the analysis of bulk samples, tablets and suspensions. The optimum chromatographic conditions for separation were established as a mobile phase comprised of acetonitrile- $0.1 \mathrm{M} \mathrm{KH}_{2} \mathrm{PO}_{4} \mathrm{pH}$ 6.5-0.1 M tetrabutyl ammonium hydroxide $\mathrm{pH}$ 6.5-water $(25: 15: 1: 59 \mathrm{v} / \mathrm{v} / \mathrm{v} / \mathrm{v})$ delivered at a flow rate of $1.0 \mathrm{~mL} / \mathrm{min}$. The stationary phase consisted of reverse-phase XTerra ${ }^{\circledR}(250 \mathrm{~mm} \times 4.6 \mathrm{~mm}$ i.d., $5 \mu \mathrm{m}$ particle size $)$ maintained at a temperature of $43{ }^{\circ} \mathrm{C}$ with a UV detection at $215 \mathrm{~nm}$. The method was found to be linear in the range $50 \%-150 \%$ $\left(r^{2}=0.997\right)$. The limits of detection and quantification were found to be $0.02 \%(20 \mu \mathrm{g})$ and $0.078 \%$ $(78 \mu \mathrm{g})$, respectively, with a $100.7 \%$ recovery of azithromycin. Degradation products of azithromycin in acidic and oxidative environments at $37^{\circ} \mathrm{C}$ were resolved from the active pharmaceutical ingredient and thus the method is fit for the purpose of drug stability confirmation.
\end{abstract}

Keywords: azithromycin; HPLC; robust; isocratic; drug stability; degradation products

\section{Introduction}

Azithromycin is a semi-synthetic macrolide antibiotic used clinically for a wide range of bacterial infections [1,2]. Azithromycin is listed in the World Health Organization and the Ministry of Health, Kenya essential medicines lists $[3,4]$ where it is indicated for the management of atypical infections. Suitable analytical methods are required to monitor the quality of azithromycin (AZT) products during manufacture, batch release and post-market surveillance. The analytical method ought to be selective for AZT in the presence of related substances, namely the synthetic intermediates azathromycin (AZA), erythromycin A oxime (EAOX) and erythromycin A imino ether (EAIE) and the degradation products $N$-demethylazithromycin (NDMAZT) and decladinosylazithromycin (DAZT) (Figure 1).

There are several published methods for the analysis of azithromycin such as biological methods [5], electroanalytical methods [6], spectrophotometric methods [7], capillary electrophoresis [8], thin layer chromatography [9] and liquid chromatography [10-13]. An excellent review of the analytical methods for azithromycin is reported by Sharma and Mullangi [14]. Liquid chromatography is the method of choice for the analysis of azithromycin in bulk samples and formulations since it is able to determine azithromycin in the presence of related substances. The current liquid chromatographic methods for the analysis of azithromycin utilize relatively expensive columns, unstable detectors and high $\mathrm{pH}$ 
and/or temperature, limiting the use of conventional silica-based columns [12,13,15]. The United States Pharmacopoeia [13] employs a mobile phase of $\mathrm{pH} 11$ with electrochemical detection while the British Pharmacopoeia [12] utilizes a polymer column with a mobile phase of $\mathrm{pH}$ 8. The electrochemical detector is not commonly available and produces unstable responses compared to the UV detector since the electrodes have direct contact with the column effluent and may react with the sample matrix while polymer columns are relatively more expensive compared to silica-based columns. This calls for use of $\mathrm{pH}$ - and temperature-stable strategies to improve on column longevity, stability and peak parameters. Such a method can be used for the routine quality control of azithromycin bulk samples and formulations as well as the market surveillance of samples. A reverse-phase high-performance liquid chromatographic method for the estimation of azithromycin suspension described by Sachin et al. [16] did not exhibit the required specificity regarding the related substances NDMAZT, AZA, DAZT, EAOX and EAIE, while the gradient method proposed by Miguel and Barbas [17] suffers from baseline instability and uses a slightly high temperature of $50^{\circ} \mathrm{C}$. This paper describes the development, validation and application of a selective, isocratic and robust liquid chromatographic method for the analysis of azithromycin in bulk samples and oral dosage forms.

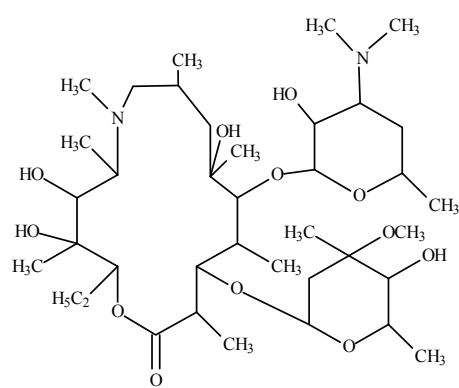

Azithromycin (AZT)

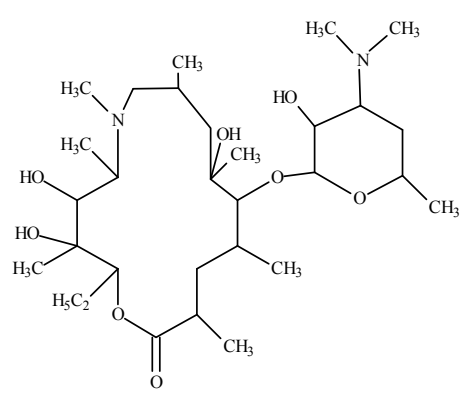

Decladinosylazithromycin (DAZT)

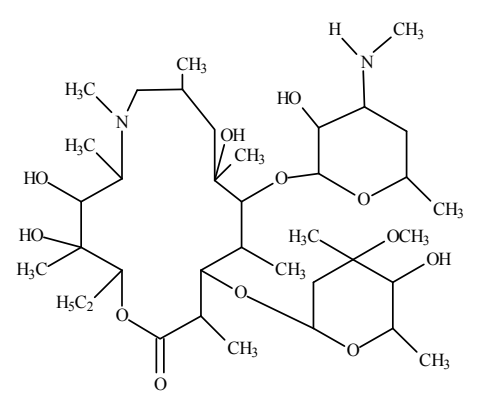

$N$-demethylazithromycin (NDMAZT)

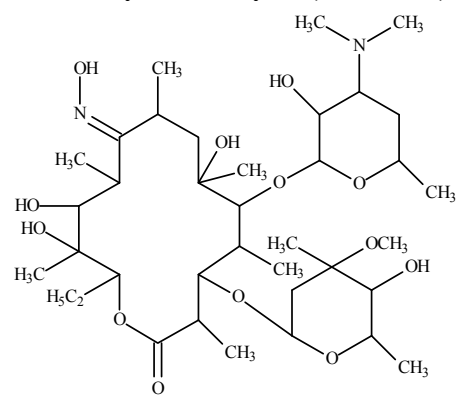

Erythromycin A oxime (EAOX)

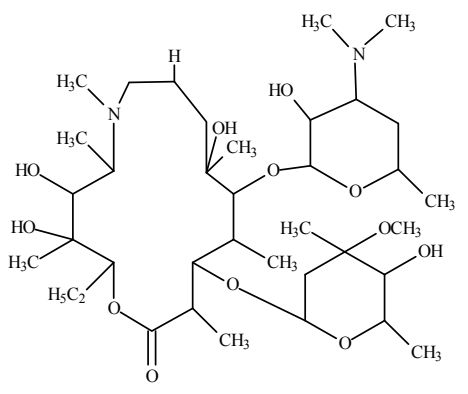

Azathromycin (AZA)

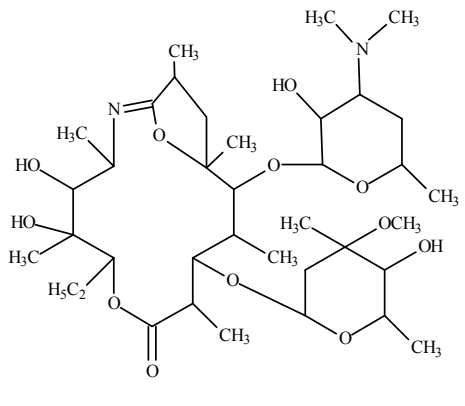

Erythromycin A imino ether (EAIE)

Figure 1. Chemical structures of azithromycin and some related substances.

\section{Materials and Methods}

\subsection{Chemicals and Reagents}

Analytical grade $\mathrm{KH}_{2} \mathrm{PO}_{4}, \mathrm{~K}_{2} \mathrm{HPO}_{4}$ and $\mathrm{H}_{3} \mathrm{PO}_{4}$ were from Loba Chemie Pvt. Ltd. (Mumbai, India) while triethylamine and triethanolamine were from BDH Laboratory Supplies (Poole, UK). Tert-butylammonium hydroxide was from Sigma-Aldrich (Steinheim, Germany). HPLC grade acetonitrile (Scharlau, Barcelona, Spain) was used as organic modifier. Purified water was prepared using distillation by GFL distillation machine type 2001/4 (Gesellschaft für Labortechnik mbH, Burgwedel, Germany). Azithromycin dihydrate working standard was donated by the Drug Analysis and Research Unit, University of Nairobi, Kenya. The working standards of erythromycin A oxime, erythromycin A imino ether, $\mathrm{N}$-demethylazithromycin, decladinosylazithromycin and azathromycin standards were purchased from Pfizer Inc. (Groton, CT, USA). Azithromycin tablets and suspensions were randomly purchased from various pharmacies in the Central Business District of the City of 
Nairobi. The innovator brand, Zithromax ${ }^{\circledR}$, was from Pfizer Laboratories Ltd. (Nairobi, Kenya). Azithromycin bulk sample was from SkyLight Chemicals (Nairobi, Kenya).

\subsection{HPLC Instruments and Analytical Conditions}

A Shimadzu high performance liquid chromatographic (HPLC) system (Shimadzu Corp., Kyoto, Japan) was used during the study. It was supported by a CBM-20A Prominence communication bus module as the system controller and an LCSolutions software Ver. 1.22, SP1 and equipped with an SPD-M20A Prominence UV/Visible photo array diode detector operating with deuterium and a tungsten lamps as UV and Visible light sources. A LC-20AD Prominence solvent delivery system with a dual-plunger tandem-flow solvent delivery system and a SIL-20AC Prominence autosampler were a part of the HPLC system. The temperature was controlled using a CTO-M20AC column oven with a block heating thermostatic chamber. Mobile phases were degassed using a Power sonic 410 bench-top ultrasonic bath (Daihan Labtech Ltd., Kyonggi-Do, Korea). A Waters XTerra ${ }^{\circledR}$, a hybrid, reverse-phase C18 column ( $250 \mathrm{~mm} \times 4.6 \mathrm{~mm}, 5 \mu \mathrm{m}$ ) (Waters Corporation, Milford, MA, USA) was used for separations. The detection wavelength was set at $215 \mathrm{~nm}$ while the sample injection volume was at $20 \mu \mathrm{L}$ and the flow rate at $1 \mathrm{~mL} / \mathrm{min}$.

\subsection{Preparation of Solutions}

\subsubsection{Working Standard Mixture}

The working standard mixture was prepared by dissolving the working standards in acetonitrile-water $(50: 50 \mathrm{v} / \mathrm{v})$ to concentrations of azithromycin $5.0 \mathrm{mg}, 1.5 \mathrm{mg}$ azathromycin, $0.64 \mathrm{mg}$ demethylazithromycin, $0.75 \mathrm{mg}$ decladinosylazithromycin, $0.304 \mathrm{mg}$ erythromycin A oxime and $0.31 \mathrm{mg}$ erythromycin A imino ether in $1 \mathrm{~mL}$ of solution. These concentrations were preferred since they yielded comparable peak heights among the related substances for accurate derivation of chromatographic parameters. The related substances have varying response factors compared to AZT. Thus erythromycin A imino ether was incorporated at $2.5 \%$ level while decladinosylazithromycin and azathromycin were at $10 \%$ level while maintaining azithromycin at $100 \%(5 \mathrm{mg} / \mathrm{mL})$. The other related substances were incorporated into the working mixture at levels ranging between $2.5 \%$ to $10 \%$ for ease of monitoring of chromatographic parameters of all components.

\subsubsection{Mobile Phases}

Mobile phases were prepared by mixing appropriate volumes $0.1 \mathrm{M} \mathrm{KH}_{2} \mathrm{PO}_{4}$ (stock solution) with water and acetonitrile. The $\mathrm{pH}$ of $0.1 \mathrm{M} \mathrm{KH}_{2} \mathrm{PO}_{4}$ had been preadjusted with an equimolar solution of $\mathrm{K}_{2} \mathrm{HPO}_{4}$. Mobile phases were degassed in an ultra-sonic water bath for $30 \mathrm{~min}$ before use.

\subsection{Peak Purity Analysis}

Peak purity analysis was performed over a wavelength range of 200-900 nm using the Shimadzu LCSolutions software Ver. 1.22 SP1 (Shimadzu, Kyoto, Japan) [18]. Although peak purity analysis does not completely prove that the peak observed is due to one component, it gives confidence in the method [19].

\subsection{Method Validation}

\subsubsection{Linearity}

Linearity was determined on solutions of azithromycin working standard within the $50 \%-150 \%$ range. For this purpose, a $5.0 \mathrm{mg} / \mathrm{mL}$ solution was taken as $100 \%$. Solutions were made by dissolving azithromycin in acetonitrile-water $(50: 50 \mathrm{v} / \mathrm{v})$ and run in triplicate. The data obtained from the linearity experiments was subjected to linear regression analysis with the concentration of injected AZT standard being plotted against the peak areas obtained. 


\subsubsection{Sensitivity}

The detection limit and limit of quantitation were determined by serially diluting $5 \mathrm{mg} / \mathrm{mL}$ AZT solution to yield signal to noise $(\mathrm{S} / \mathrm{N})$ ratios of 3 and 10 respectively [20].

\subsubsection{Accuracy}

Accuracy was evaluated by analyzing synthetic mixtures spiked with known quantities of azithromycin. Triplicate determinations at three concentration levels $(80 \%, 100 \%$ and $120 \%)$ were used. The mean recoveries of the assays were assessed for compliance with the International Conference on Harmonization (ICH) guidelines [20].

\subsubsection{Robustness}

The Box-Wilson Design (BWD) was used to determine the optimum range of the chromatographic factors within which the method was robust. A three-level $(-1,0$ and +1$)$ experimental design was applied out as shown in Table 1. The experiments were randomized with the aid of the Statgraphics Centurion XVI (StatPoint Technologies Inc., Warrento, VA, USA) software. The interactive effects of the three variables of temperature, acetonitrile concentration and buffer $\mathrm{pH}$ on the selectivity of the critical peak pair of EAIE and AZT were evaluated as a measure of robustness. Pareto analysis was used to identify the interactive effects that had the greatest impact $(p<0.05)$ on the selectivity of the critical pair of EAIE and AZT.

Table 1. Nominal values corresponding to low, central and high levels.

\begin{tabular}{cccc}
\hline Factor & Low Level (-1) & Central Level (0) & High Level (+1) \\
\hline $\mathrm{pH}$ & 6.0 & 6.5 & 7.0 \\
Acetonitrile $(\%$ vol. $)$ & 22 & 25 & 28 \\
Temperature $\left({ }^{\circ} \mathrm{C}\right)$ & 41 & 43 & 45 \\
\hline
\end{tabular}

\subsubsection{Precision}

The parameters of repeatability and intermediate precision were evaluated as indicators of precision according to ICH guidelines [20]. Repeatability was determined by a six times injection of azithromycin working solution while intermediate precision was evaluated by injecting five replicate solutions of azithromycin working standard over three consecutive days. A coefficient of variation $(\mathrm{CV})$ of $<1.5 \%$ of the replicate injections was used as an acceptance criteria for method precision [20].

\subsubsection{Specificity}

The ability of the proposed analytical method to unequivocally assess azithromycin in the presence of the related substances was investigated by determining the resolution between azithromycin and all other components according to ICH guidelines [20].

\subsection{Assay of Azithromycin in Bulk Samples, Tablets and Suspensions}

Twenty tablets were weighed and pulverized using a mortar and pestle and powder equivalent to $250 \mathrm{mg}$ azithromycin was transferred into a $50 \mathrm{~mL}$ volumetric flask and dissolved in $25 \mathrm{~mL}$ acetonitrile under sonication for $15 \mathrm{~min}$ before making up to volume with distilled water. The samples were filtered through a $0.45 \mu \mathrm{m}$ membrane filter before chromatography.

Suspensions equivalent to $40 \mathrm{mg} / \mathrm{mL}$ were weighed into $5 \mathrm{~mL}$ volumetric flasks and dissolved in $2.5 \mathrm{~mL}$ of acetonitrile under sonication for $15 \mathrm{~min}$ before making up to volume with distilled water. The sample was filtered through a $0.45 \mu \mathrm{m}$ membrane filter before chromatographic analysis. Azithromycin bulk sample was prepared by dissolving $50 \mathrm{mg}$ in $25 \mathrm{~mL}$ of acetonitrile under sonication before diluting to $50 \mathrm{~mL}$ with distilled water. The test and standard solutions were run under the 
optimum HPLC conditions and the peak areas obtained were used for the determination of the content of AZT in the samples.

\subsection{Forced Degradation and Stability-Indicating Study}

Solutions of azithromycin working standard were subjected to stress testing under oxidative and acidic conditions. The stability indicating ability of the method was tested under these two conditions.

\subsubsection{Oxidative Degradation of Azithromycin}

Oxidation was carried out using $0.0005 \% v / v \mathrm{H}_{2} \mathrm{O}_{2}$ as described by Abuga et al. for clarithromycin [21] and the solutions sampled at defined intervals for HPLC analysis. For this purpose, azithromycin $5 \mathrm{mg} / \mathrm{mL}$ solution was incubated in $0.0005 \% v / v \mathrm{H}_{2} \mathrm{O}_{2}$ at $37{ }^{\circ} \mathrm{C}$ and the peak areas of AZT were monitored over a period of $7 \mathrm{~h}$. To determine the order of reaction, the data was fitted into zero, first and second order kinetic models whereby the $r^{2}$ value of the linear plots was used as a measure of goodness of fit.

\subsubsection{Degradation of Azithromycin in Acid}

Acid degradation was carried out by incubating a $5 \mathrm{mg} / \mathrm{mL}$ solution of AZT in $0.1 \mathrm{M} \mathrm{H}_{3} \mathrm{PO}_{4}$ ( $\mathrm{pH} 1.60), 0.05 \mathrm{M} \mathrm{H}_{3} \mathrm{PO}_{4}(\mathrm{pH} 1.68), 0.025 \mathrm{M} \mathrm{H}_{3} \mathrm{PO}_{4}(\mathrm{pH} 1.92)$ and $0.01 \mathrm{M} \mathrm{H}_{3} \mathrm{PO}_{4}(\mathrm{pH} 2.37$ ), respectively, at $37{ }^{\circ} \mathrm{C}$ using the procedure previously described in literature [21]. The peak area of AZT was monitored by HPLC-UV under the optimized conditions.

\section{Results and Discussion}

\subsection{Method Development and Optimization}

The development of the HPLC method followed a systematic manipulation of the chromatographic factors of $\mathrm{pH}$, temperature, organic modifier concentration and buffer concentration. The process involved the selection of appropriate conditions and their optimization. These conditions included the type of column packing, column dimensions, mobile phase composition and flow rate, oven temperature, sample amount and detection wavelength. A detection wavelength of $215 \mathrm{~nm}$ was selected on account of better baseline stability while maintaining acceptable sensitivity.

The UV spectra obtained for the impurities used in this study did not show appreciable absorption differences. Acetonitrile was selected as the organic modifier because it has a higher eluting power and a lower UV cut-off compared to methanol. A Waters XTerra ${ }^{\circledR}$ hybrid, reverse-phase C18 column $(250 \mathrm{~mm} \times 4.6 \mathrm{~mm}, 5 \mu \mathrm{m})$ was chosen for this study since it gave the highest efficiency with regard to the number of theoretical plates compared to Phenomenex Luna ${ }^{\circledR}$ and Phenomenex Gemini ${ }^{\circledR}$ of similar dimensions.

The effect of adjusting the $\mathrm{pH}$ of the phosphate buffer on the separation and symmetry of components was investigated using mobile phases at $\mathrm{pH}$ 5.0,6.0,6.5 and 7.0. A plot of capacity factor versus $\mathrm{pH}$ (Figure 2) revealed that an increase in buffer $\mathrm{pH}$ improved the selectivity and also increased the retention times of all the components. Furthermore, an improved peak shape was observed with the increase in pH. However, at pH 7.0 there was co-elution of AZT and EAIE while at pH 6.0 there was poor resolution between AZT and NDMAZT. Through several experiments, AZT and EAIE were identified as the critical peak pair (CPP) and it was used as an indicator of the method's performance. 


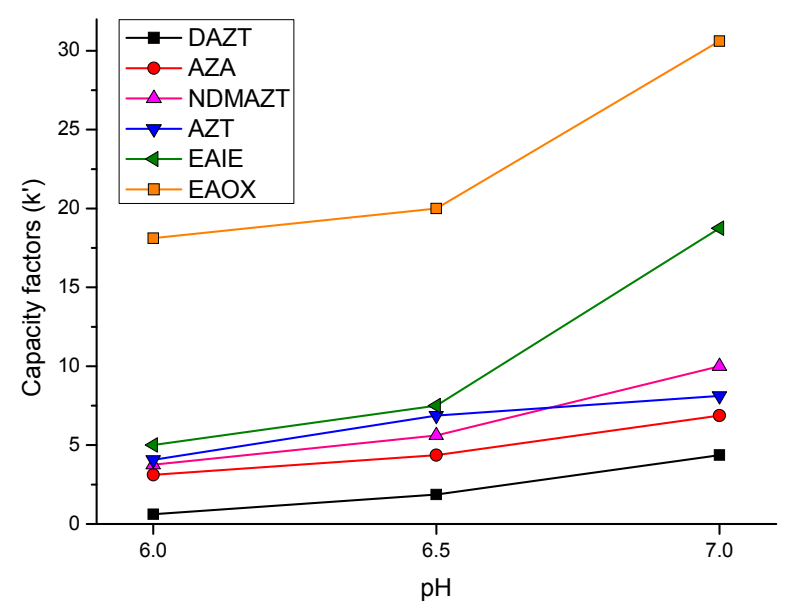

Figure 2. Effect of buffer $\mathrm{pH}$ on capacity factors of components of the working mixture.

To improve the separation between AZT and EAIE, the proportion of the organic modifier was reduced to $20 \%$ while maintaining $\mathrm{pH}$ 6.5. Under these chromatographic conditions, partial resolution was achieved, although the run time increased from 60 to $100 \mathrm{~min}$. To achieve baseline resolution, the incorporation of tetrabutylammonium hydroxide at a concentration of $1 \%$ led to a shorter run time (45 min) but with decreased resolution of decladinosylazithromycin (DAZT) with the solvent front. The other ion-pairing agents used, namely triethanolamine and triethylamine, yielded poorer peak parameters compared to tetrabutylammonium hydroxide. To improve the resolution and peak symmetry factor of DAZT, the effect of the buffer concentration was investigated in the range of $10 \%-25 \%$ at $5 \%$ intervals. A buffer concentration of $15 \%$ was found to be optimal. In order to reduce the run time with baseline resolution of all components, the concentrations of acetonitrile and temperature were optimized to $25 \% v / v$ and $43{ }^{\circ} \mathrm{C}$, respectively. Under these conditions, the peaks of all separated components had peak purities of unity.

The optimum chromatographic conditions for the separation of all components were established as a mobile phase comprised of acetonitrile- $0.1 \mathrm{M} \mathrm{KH}_{2} \mathrm{PO}_{4} \mathrm{pH}$ 6.5-0.1 $\mathrm{M}$ tetrabutyl ammonium hydroxide $\mathrm{pH}$ 6.5-water (25:15:1:59 $\mathrm{v} / \mathrm{v} / \mathrm{v} / \mathrm{v})$. Figure 3 shows a typical chromatogram obtained under the optimum conditions.

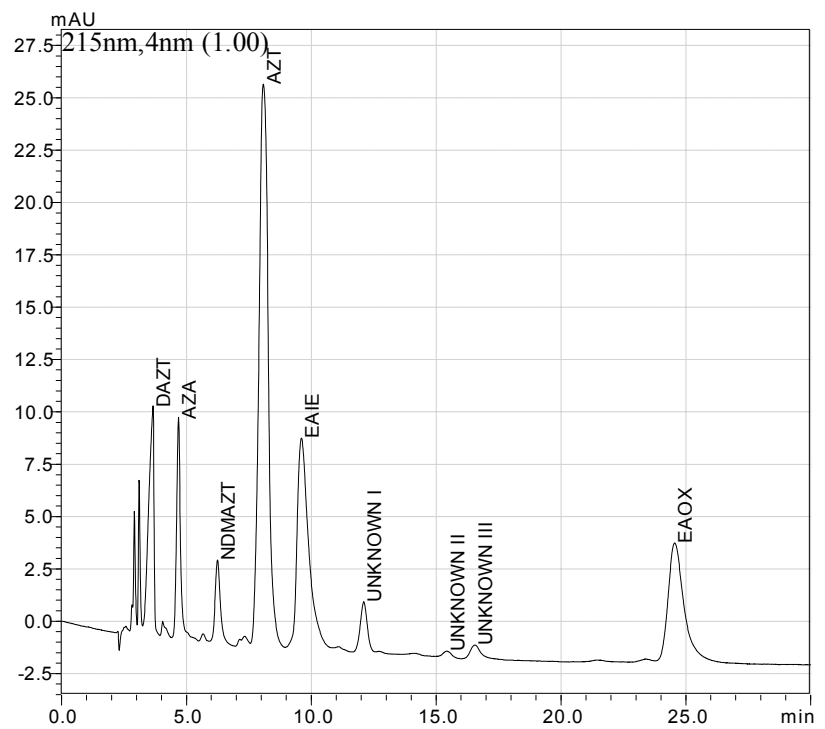

Figure 3. Typical chromatogram of the working mixture obtained under optimized chromatographic conditions. 


\subsection{Method Validation}

\subsubsection{Linearity}

The linear regression equation was $y=9948 x-40457$ with a coefficient of determination $\left(r^{2}\right)$ of 0.997, where $y=$ peak area and $x=$ concentration of the solution. The coefficients of variation (CV) of the peak areas obtained ranged between $0.02 \%-0.12 \%$ while the standard errors of the slope and intercept were 0.04 and 0.21 , respectively. The developed method therefore met the ICH guidelines for linearity over the concentration range investigated [20,22].

\subsubsection{Sensitivity}

When calculated against a sample solution of $5.0 \mathrm{mg} / \mathrm{mL}$, the (the limit of dection) LOD was $0.02 \%(20 \mu \mathrm{g})(n=6)$ at a S/N ratio of 3 while the limit of quantitation (LOQ) was $0.078 \%(78 \mu \mathrm{g})(n=6)$ at a $\mathrm{S} / \mathrm{N}$ ratio of 10 . The LOD and LOQ results obtained demonstrated that the developed method was adequately sensitive for the determination of AZT and its related substances at the $0.1 \%$ level $[20,22]$.

\subsubsection{Accuracy}

The results for the recovery of azithromycin from spiked samples are shown in Table 2 . The ICH guidelines for the validation of analytical procedures specify a mean recovery of $100 \% \pm 2.0 \%$ at each concentration over the range of $80 \%-120 \%$ of nominal concentration [20]. The results shown in Table 2 indicate that the developed method is accurate with a mean recovery of $100.7 \%$.

Table 2. Recovery of azithromycin from spiked samples. CV; coefficient of variation.

\begin{tabular}{cccccc}
\hline \multirow{2}{*}{$\begin{array}{c}\text { Target } \\
\text { Concentration (\%) }\end{array}$} & $\begin{array}{c}\text { Amount Added } \\
(\mathbf{m g} / \mathbf{m L})\end{array}$ & $\begin{array}{c}\text { Amount Recovered } \\
(\mathbf{m g} / \mathbf{m L})\end{array}$ & $\begin{array}{c}\text { Recovery } \\
(\text { Absolute \%) }\end{array}$ & $\begin{array}{c}\text { Recovery } \\
\text { (CV \%) }\end{array}$ & $\begin{array}{c}\text { Mean } \\
\text { Recovery (\%) }\end{array}$ \\
\hline 80 & 4.98 & 4.975 & 99.9 & 0.16 & \\
100 & 5.08 & 5.171 & 101.8 & 0.20 & 100.7 \\
120 & 5.13 & 5.152 & 100.4 & 0.50 & \\
\hline
\end{tabular}

\subsubsection{Robustness}

The robustness ranges for $\mathrm{pH}$ were found to be $\mathrm{pH} 6-7$, with $22 \%-28 \% v / v$ acetonitrile and $41-45{ }^{\circ} \mathrm{C}$ for the column temperature. Pareto analysis revealed that the acetonitrile concentration and buffer $\mathrm{pH}$ had the biggest impact on the separation of AZT and EAIE ( $p=0.05)$. The response surface plot (Figure 4) showed the non-intersection of the response surface plots at all nominal values investigated, indicating that there was no co-elution of this critical peak.

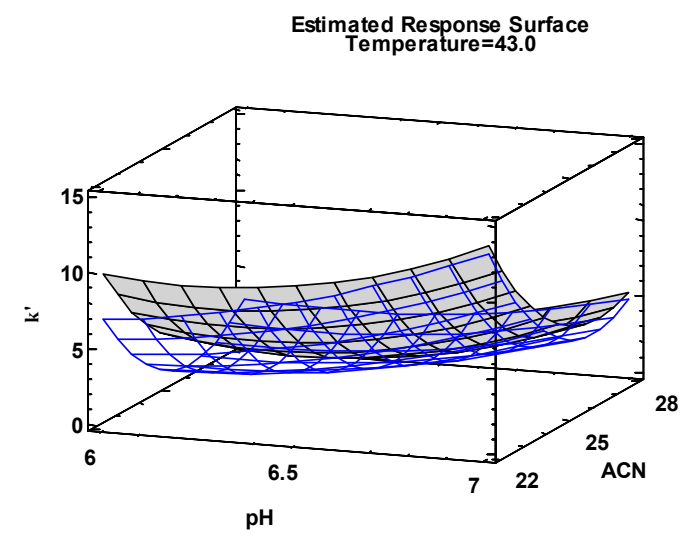

Figure 4. Overlaid response surfaces of AZT and EAIE. The blue and grey coloured surfaceslines represent the individual response surfaces of EAIE and AZT respectively. 


\subsubsection{Precision}

The CV of the peak areas obtained from repeatability experiments was $0.97 \%$ while that for intermediate precision was in the range of $0.06 \%-0.11 \%$. In all the determinations the $\mathrm{CV}$ was $<1.5 \%$, and thus the proposed method was found to be precise [20].

\subsubsection{Specificity}

The resolution between azithromycin and all other components was $>1.5$, and thus the proposed method demonstrated sufficient specificity for analysis of azithromycin in accordance with ICH guidelines [20].

\subsection{Forced Degradation of Azithromycin in Acidic and Oxidative Environments}

The data generated from the oxidative degradation of azithromycin fitted into the second-order rate equation with the linear regression equation $y=0.0106 x+0.1377\left(r^{2}=0.994\right)$, a half life of $13 \mathrm{~min}$ and a rate constant $(\mathrm{k})$ of $1.06 \times 10^{-2}$ area units ${ }^{-1} \cdot \mathrm{min}^{-1}$. This oxidative study may be indicative of the possible nature of degradation of AZT in the presence of oxidants and exposure to air during storage.

Acid degradation data showed that AZT degrades rapidly by about $90 \%$ within $10 \mathrm{~min}$ in $0.1 \mathrm{M} \mathrm{H}_{3} \mathrm{PO}_{4}$ and $0.05 \mathrm{M} \mathrm{H}_{3} \mathrm{PO}_{4}$ solutions maintained at $37^{\circ} \mathrm{C}$. However, at $0.025 \mathrm{M} \mathrm{H}_{3} \mathrm{PO}_{4}$ at $37^{\circ} \mathrm{C}$, the kinetics of AZT decomposition were derivable. The data generated fitted into the first-order rate equation with the linear regression equation $y=-0.0002 x+13.651\left(r^{2}=0.9907\right)$, a half life of $57.8 \mathrm{~h}(3465 \mathrm{~min})$ and a rate constant $(\mathrm{k})$ of $2.0 \times 10^{-4} \mathrm{~min}^{-1}$. In all instances, the degradation products in acid were well separated from the AZT peak, thus providing further evidence for the stability-indicating ability of the method. The degradation of AZT under acidic conditions is likely to affect oral bioavailability and efficacy of the drug due to gastric acid. For instance, with a mean gastric residence time for the AZT base as low as $10 \mathrm{~min}$ in gastric fluid of $\mathrm{pH} 1.6,93 \%$ of the administered dose may be lost due to degradation. The degradation of AZT in gastric fluid may differ since there is a significant concentration gradient of the drug from gastric tissue to gastric juice [23].

\subsection{Assay of Azithromycin Tablets and Suspensions}

The developed and validated liquid chromatographic method was applied for the assay of azithromycin bulk samples and the oral dosage formulations of tablets and suspensions. The product excipients did not interfere with the determination of AZT in all the formulations analyzed. The peak purity index of AZT was confirmed to be unity by photo diode array analysis.

The United States Pharmacopeia (2015) limits for assay (90.0\%-110.0\% label claim) of azithromycin were adopted for quality assessment of the samples [13]. The assay test failure rates were $23 \%(n=13)$ for tablet brands, $60 \%(n=5)$ for premixed suspensions and $25 \%(n=4)$ for dry powders (Table 3 ). There was a relatively higher assay test failure rate for premixed suspensions compared to dry powders for reconstitution. These findings underscore the need for generic manufacturers to carry out comprehensive formulation studies to justify any formulation aspects that significantly differ from those of the innovator products. The Drug Regulatory Authorities ought to evaluate supporting data for products that deviate from the innovator formulation to ensure that generics registered are pharmaceutically equivalent and bioequivalent to the innovator brand. Where significant changes in formulation occur, the generic manufacturer should carry out full clinical studies to support the rationale for such deviation [24].

The assay test failure rates observed underscore the need for continuous market surveillance on products available in the Kenyan market to ensure the circulation of good quality medicines. This will help curb the emergence of macrolide-resistant strains, thus preserving the antibiotic arsenal to treat susceptible microorganisms. Batch-to-batch variation of AZT content was not observed where different batches of the same product were analyzed (Table 3). 
Table 3. Assay results for selected commercial samples of azithromycin. The figures in parentheses represent the coefficient of variation; P, Powder for reconstitution; M, Premixed; a and b represent different batches of each product.

\begin{tabular}{|c|c|c|c|}
\hline Product Code & Formulation & AZT Content (\%) & Remarks \\
\hline \multirow[t]{2}{*}{ I } & (a) Tablet & $93.6(1.6)$ & Complied \\
\hline & (b) Tablet & $94.8(1.0)$ & Complied \\
\hline \multirow[t]{2}{*}{ II } & (a) Tablet & $110.3(0.2)$ & Complied \\
\hline & (b) Tablet & $109.1(0.1)$ & Complied \\
\hline \multirow[t]{2}{*}{ III } & (a) Tablet & $98.5(0.5)$ & Complied \\
\hline & (b) Tablet & $99.2(0.3)$ & Complied \\
\hline \multirow[t]{2}{*}{ IV } & (a) Tablet & $97.2(0.2)$ & Complied \\
\hline & (b) Tablet & $97.6(0.2)$ & Complied \\
\hline $\mathrm{V}$ & Tablet & $102.0(1.5)$ & Complied \\
\hline \multirow[t]{2}{*}{ VI } & (a) Tablet & $109.9(0.3)$ & Complied \\
\hline & (b) Tablet & $107.3(0.3)$ & Complied \\
\hline \multirow{2}{*}{ VII } & (a) Tablet & $105.1(1.6)$ & Complied \\
\hline & (b) Tablet & $104.3(1.3)$ & Complied \\
\hline \multirow[t]{2}{*}{ VIII } & (a) Suspension (M) & $110.0(0.6)$ & Complied \\
\hline & (b) Suspension (M) & $109.3(0.5)$ & Complied \\
\hline \multirow[t]{2}{*}{ IX } & (a) Suspension (M) & $96.4(0.7)$ & Complied \\
\hline & (b) Suspension (M) & $96.1(0.2)$ & Complied \\
\hline$x$ & Suspension (M) & $69.3(1.7)$ & Did not comply \\
\hline XI & Suspension (M) & $89.3(0.4)$ & Did not comply \\
\hline XII & Tablet & $81.4(0.5)$ & Did not comply \\
\hline XIII & Tablet & $99.8(0.3)$ & Complied \\
\hline XIV & Tablet & $83.3(0.2)$ & Did not comply \\
\hline $\mathrm{XV}$ & Tablet & $87.0(1.1)$ & Did not comply \\
\hline XVI & Tablet & $103.3(1.3)$ & Complied \\
\hline XVII & Suspension $(\mathrm{P})$ & $88.6(0.2)$ & Did not comply \\
\hline XVIII & Suspension $(\mathrm{P})$ & $105.5(0.4)$ & Complied \\
\hline XIX & Suspension (M) & $87.8(1.3)$ & Did not comply \\
\hline$X X$ & Suspension $(\mathrm{P})$ & $98.7(0.7)$ & Complied \\
\hline Bulk sample & Powder & $94.7(0.1)$ & Complied \\
\hline Zithromax $^{\circledR}$ & Suspension $(\mathrm{P})$ & $99.6(0.7)$ & Complied \\
\hline Zithromax $^{\circledR}$ & Tablet & $96.4(1.5)$ & Complied \\
\hline
\end{tabular}

\section{Conclusions}

A selective, simple, specific, robust and isocratic liquid chromatographic method for the analysis of azithromycin in bulk samples and oral dosage forms was developed. The method met ICH guidelines for validation parameters. With a run time of $25 \mathrm{~min}$, the method allows a relatively high sample throughput. Therefore, the method may be employed in the routine laboratory analysis of samples and stability studies. The presence of products that do not meet assay specifications in the market is a matter of public health concern and it underscores the need for sustained post-market surveillance by the Drug Regulatory Authority (DRA). This study did not encounter any counterfeits of AZT on the market.

Acknowledgments: The authors wish to thank the management of the National Quality Control Laboratory for granting permission to use equipment, as well as the Drug Analysis and Research Unit of the University of Nairobi for logistical support and providing instruments to undertake this research.

Author Contributions: Alex O. Okaru, Kennedy O. Abuga, Franco N. Kamau and Stanley N. Ndwigah conceived the study. Alex O. Okaru, Kennedy O. Abuga and Dirk W. Lachenmeier helped to draft the manuscript, organized data and revised the final version of the manuscript. All authors contributed to the interpretation of findings, read and approved the final manuscript.

Conflicts of Interest: The authors declare no conflict of interest. 


\section{References}

1. Piscitelli, S.C.; Danziger, L.H.; Rodvold, K.A. Clarithromycin and azithromycin: New macrolide antibiotics. Clin. Pharm. 1992, 11, 137-152. [PubMed]

2. Stott, G.A. New macrolide antibiotics: Clarithromycin and azithromycin. Am. Fam. Physician 1992, 46, 863-869. [PubMed]

3. World Health Organization (WHO). WHO Model Essential Medicines List 2015; World Health Organization: Geneva, Switzerland, 2015.

4. Ministry of Health. Kenya Essential Medicines List 2016; Ministry of Health: Nairobi, Kenya, 2016.

5. Breier, A.R.; Garcia, C.V.; Oppe, T.P.; Steppe, M.; Schapoval, E.E.S. Microbiological assay for azithromycin in pharmaceutical formulations. J. Pharm. Biomed. Anal. 2002, 29, 957-961. [CrossRef]

6. Nigović, B.; Šimunić, B. Voltammetric assay of azithromycin in pharmaceutical dosage forms. J. Pharm. Biomed. Anal. 2003, 32, 197-202. [CrossRef]

7. Walash, M.I.; Rizk, M.S.; Eid, M.I.; Fathy, M.E. Spectrophotometric determination of four macrolide antibiotics in pharmaceutical formulations and biological fluids via binary complex formation with eosin and spectrophotometry. J. AOAC Int. 2007, 90, 1579-1587. [PubMed]

8. Zhang, S.; Huang, X.; Yao, N.; Horváth, C. Preparation of monodisperse porous polymethacrylate microspheres and their application in the capillary electrochromatography of macrolide antibiotics. J. Chromatogr. A 2002, 948, 193-201. [CrossRef]

9. Khedr, A.; Sheha, M. Quantitative thin-Layer chromatographic method of analysis of azithromycin in pure and capsule forms. J. Chromatogr. Sci. 2003, 41, 10-16. [CrossRef] [PubMed]

10. Kamau, F.N.; Chepkwony, H.K.; Ngugi, J.K.; Debremaeker, D.; Roets, E.; Hoogmartens, J. Isocratic liquid chromatographic method for the analysis of azithromycin and its structurally related substances in bulk samples. J. Chromatogr. Sci. 2002, 40, 529-533. [CrossRef] [PubMed]

11. Debremaeker, D.; Visky, D.; Chepkwony, H.K.; van Schepdael, A.; Roets, E.; Hoogmartens, J. Analysis of unknown compounds in azithromycin bulk samples with liquid chromatography coupled to ion trap mass spectrometry. Rapid Commun. Mass Spectrom. 2003, 17, 342-350. [CrossRef] [PubMed]

12. British Pharmacopoeia Commission. British Pharmacopoeia 2015; The Stationery Office Ltd.: Norwich, UK, 2014.

13. United States Pharmacopeial. USP 38-NF 33; United States Pharmacopeial Convention: Rockville, MD, USA, 2015.

14. Sharma, K.; Mullangi, R. A concise review of HPLC, LC-MS and LC-MS/MS methods for determination of azithromycin in various biological matrices. Biomed. Chromatogr. 2013, 27, 1243-1258. [CrossRef] [PubMed]

15. El-Gindy, A.; Attia, K.A.; Nassar, M.W.; Al Abasawi, N.M.; Al-Shabrawi, M. Optimization and validation of a stability-indicating RP-HPLC method for determination of azithromycin and its related compounds. J. AOAC Int. 2011, 94, 513-522. [PubMed]

16. Sachin, K.S.; Prakash, D.; Tamizh, M.T. Development and validation of stability indicating UV spectrophotometric method for the estimation of azithromycin suspension. Int. J. ChemTech Res. 2010, 2, 1939-1944.

17. Miguel, L.; Barbas, C. LC determination of impurities in azithromycin tablets. J. Pharm. Biomed. Anal. 2003, 33, 211-217. [CrossRef]

18. Stahl, M. Peak Purity Analysis in HPLC and CE Using Diode-Array Technology. Available online: http://www.agilent.com/cs/library/applications/5988-8647EN.pdf (accessed on 24 April 2016).

19. Wiberg, K.; Andersson, M.; Hagman, A.; Jacobsson, S.P. Peak purity determination with principal component analysis of high-performance liquid chromatography-diode array detection data. J. Chromatogr. A 2004, 1029, 13-20. [CrossRef] [PubMed]

20. ICH Q2 (R1) Validation of Analytical Procedures: Text and Methodology. Available online: http://www.ich. org/fileadmin/Public_Web_Site/ICH_Products/Guidelines/Quality/Q2_R1/Step4/Q2_R1_Guideline.pdf (accessed on 10 April 2016).

21. Abuga, K.O.; Chepkwony, H.K.; Roets, E.; Hoogmartens, J. A Stability-indicating HPLC method for the separation of clarithromycin and its related substances in bulk Samples. J. Sep. Sci. 2001, 24, 849-855. [CrossRef] 
22. ICH Q6A Specifications: Test Procedures and Acceptance Criteria for New Drug Substance and New Drug Products: Chemical Substances. Available online: http://www.fda.gov/Drugs/ GuidanceComplianceRegulatoryInformation/Guidances/ucm134966.htm (accessed on 10 April 2016).

23. Harrison, J.D.; Jones, J.A.; Morris, D.L. Azithromycin levels in plasma and gastric tissue, juice and mucus. Eur. J. Clin. Microbiol. Infect. Dis. 1991, 10, 862-864. [CrossRef] [PubMed]

24. FDA Guidance for Industry Bioavailability and Bioequivalence Studies for Orally Administered Drug Products-General Guidance for Industry Bioavailability and Bioequivalence. Available online: http://www. fda.gov/downloads/Drugs/DevelopmentApprovalProcess/HowDrugsareDevelopedandApproved/ ApprovalApplications / AbbreviatedNewDrugApplicationANDAGenerics/UCM154838.pdf (accessed on 12 April 2016).

(C) 2017 by the authors. Licensee MDPI, Basel, Switzerland. This article is an open access article distributed under the terms and conditions of the Creative Commons Attribution (CC BY) license (http://creativecommons.org/licenses/by/4.0/). 